\title{
Interactions between Heterotypic Stressors and Corticosterone Reveal Integrative Mechanisms for Controlling Corticotropin-Releasing Hormone Gene Expression in the Rat Paraventricular Nucleus
}

\author{
Alan G. Watts and Graciela Sanchez-Watts \\ The Neuroscience Program and the Department of Biological Sciences, University of Southern California, Los Angeles, \\ California 90089-2520
}

Although the convergence of neural and humoral afferent information onto paraventricular neuroendocrine corticotropinreleasing hormone $(\mathrm{CRH})$ neurons is a major determinant for adaptive stress responses, the underlying integrative mechanisms are poorly understood. To dissect the relative contributions made by neural afferents and corticosterone to these processes, we determined how the concurrent application of two heterotypic physiological stressors, chronic dehydration (produced by drinking hypertonic saline) and sustained hypovolemia (produced by subcutaneous injections of polyethylene glycol), is interpreted by the synthetic and secretory activity of $\mathrm{CRH}$ neurons using in situ hybridization and plasma ACTH measurements. These two stressors are encoded by relatively simple, distinct, and well defined sets of neural afferents to $\mathrm{CRH}$ neurons. Both increase plasma corticosterone, but they have opposing actions on $\mathrm{CRH}$ gene expression when applied separately. In the first experiment, we showed that chronic dehy- dration suppresses $C R H$ gene transcription after hypovolemia, but not the preproenkephalin and c-fos mRNA responses or ACTH secretion. In the second, we showed that negative feedback actions of corticosterone do not suppress $\mathrm{CRH}$ gene activation after hypovolemia, but instead determine the prestress lower limit of a range within which the $\mathrm{CRH}$ gene then responds. Collectively, these data show that at least two processes are integrated to control how the $\mathrm{CRH}$ gene responds to multiple stimuli. First, the presence of corticosterone, which although permissive for appropriately activating the $\mathrm{CRH}$ gene during hypovolemia, does not mediate the suppressed gene response. Second, neural afferent-driven processes that encode dehydration play a central role in suppressing $\mathrm{CRH}$ activation.

Key words: corticosterone; stress; adaptation; integration; neuropeptides; afferent control
The medial parvicellular paraventricular nucleus (PVHmp) is the focus for the neural control of the hypothalamo-pituitary-adrenal axis. A subset of PVHmp neurons synthesize the corticotropinreleasing hormone $(\mathrm{CRH})$ and arginine vasopressin (AVP) released into hypophysial portal blood, which in turn control the synthesis and release of ACTH from corticotropes. CRH neurons receive diverse sets of neural and humoral inputs, particularly corticosterone, which are integrated by the PVHmp to provide coordinated and adaptive hormone release.

To maintain the viable pool of releasable $\mathrm{CRH}$ within terminals of neuroendocrine neurons, stimuli that increase ACTH release are generally accompanied by increased $C R H$ gene transcription and synthesis of the bioactive peptide. Thus, many stressors increase CRH heteronuclear (hn) RNA (the primary gene transcript) and CRH mRNA levels (Kovács and Sawchenko, 1996a,b; Ma et al., 1997a; Tanimura et al., 1998). However, it is unclear how the stimulus/synthesis/secretion sequence for CRH is controlled by the neural processes that integrate inputs to the

Received Jan. 25, 2002; revised April 10, 2002; accepted May 7, 2002.

This study was supported by Grant NS29728 from the National Institute of Neurological Disorders and Stroke, National Institutes of Health. We are grateful to Dr. Susan Tanimura for technical assistance. We thank Drs. Tom Curran, Joseph Majzoub, Steven Sabol, and Robert Thompson for the cDNAs used to generate riboprobes for in situ hybridization.

Correspondence should be addressed to Dr. Alan G. Watts, Hedco Neuroscience Building, MC 2520, University of Southern California, 3641 Watt Way, Los Angeles, CA 90089-2520. E-mail: watts@usc.edu.

Copyright (C) 2002 Society for Neuroscience $\quad 0270-6474 / 02 / 226282-08 \$ 15.00 / 0$
PVHmp and ultimately determine adaptive neuroendocrine responses to stress.

We have investigated this integrative process by determining how neuropeptide genes respond to an acute stressor that normally stimulates their expression (sustained hypovolemia) when it is presented together with a heterotypic chronic stressor that depresses $\mathrm{CRH}$ gene expression (cellular dehydration; DE). Because these stressors mediate their opposing effects on gene expression using simple, restricted, and well defined sets of neural afferents (Kovács and Sawchenko, 1993; Pacák and Palkovits, 2001; Watts, 2001), how they interact when presented concurrently should provide insights about integrative processes in a way not possible using more complex stressors.

Sustained hypovolemia, as evoked by injections of polyethylene glycol (PEG), produces intensity-dependent increases in ACTH and corticosterone secretion lasting at least $5 \mathrm{hr}$ (Stricker et al., 1979; Tanimura et al., 1998). Increased ACTH secretogogue release is followed by pronounced activation of CRH and other neuropeptide genes (Watts and Sanchez-Watts, 1995b; Tanimura et al., 1998). However, AVP gene expression is not increased by hypovolemia (Tanimura et al., 1998). The response of neuroendocrine $\mathrm{CRH}$ neurons to the DE evoked by increasing plasma osmolality is quite different. DE maintained for up to $5 \mathrm{~d}$ increases plasma corticosterone concentrations and slowly decreases levels of CRH biosynthesis (Young, 1986; Dohanics et al., 1990a; Watts, 1992; Watts et al., 1995; Kay-Nishiyama and Watts, 
1999). DE also reduces the ACTH secretory response to some stressors (Dohanics et al., 1990b; Aguilera et al., 1993).

Corticosterone is generally regarded as a simple negative feedback signal that regulates $C R H$ gene expression in the basal state and during stress, although the underlying mechanisms have proved remarkably elusive (Watts, 1996; Kovács et al., 2000). Corticosterone controls the onset, magnitude, and duration of the neuroendocrine $\mathrm{CRH}$ gene response to hypovolemia (Tanimura and Watts, 1998, 2000), whereas circulating corticosterone is a prerequisite for DE-associated reductions in CRH mRNA (Watts and Sanchez-Watts, 1995b). To determine what role corticosterone might play in the integrative control of $C R H$ gene expression, we also measured in adrenalectomized (ADX) rats how different corticosterone concentrations affected the magnitude of the $\mathrm{CRH}$ mRNA response to PEG injections.

\section{MATERIALS AND METHODS}

Animals and treatments. Adult male Sprague Dawley rats (225-250 gm body weight at the beginning of the experiment) were maintained on a 12 hr light/dark photoperiod (lights on at 6:00 A.M.) with ad libitum access to water and rat chow and were allowed at least $5 \mathrm{~d}$ of acclimation to the animal quarters. At this time (day 0) one batch of rats was divided initially into two groups: (1) animals maintained on water and (2) animals given $2.5 \%$ saline (w/v) to drink for $3 \mathrm{~d}$. This exposure to DE was chosen because this was the minimum length of time required to reduce CRH mRNA in the PVHmp (Watts et al., 1995).

On the morning of day 3 (6:30-7:30 A.M.), food and water or saline were removed from both groups and rats were briefly anesthetized with halothane. Rats in both groups were then given subcutaneous injections of either $5 \mathrm{ml}$ of $40 \%$ PEG (MW 8000; Sigma, St. Louis, MO) dissolved in $0.9 \%$ saline or $5 \mathrm{ml} 0.9 \%$ saline and left undisturbed until they were killed $5 \mathrm{hr}$ later. Injections were given through a small incision in the midline of the back using a $10 \mathrm{~cm}, 21 \mathrm{gm}$ blunt needle directed toward the neck. The incision was sealed using a wound clip to prevent leakage.

Rats from each of the treatment groups were then killed in one of two ways. Some were deeply anesthetized by intraperitoneal injection of tribromoethanol, and a single $1-1.5 \mathrm{ml}$ blood sample was taken from the external jugular vein into a heparinized syringe for hematocrit and osmolality measurements. Animals were then perfused through the ascending aorta with a brief saline rinse followed by $500 \mathrm{ml}$ of ice-cold $4 \%$ paraformaldehyde solution in $0.1 \mathrm{M}$ borate buffer, $\mathrm{pH}$ 9.5. After perfusion, the brain from each animal was removed and postfixed overnight at $4^{\circ} \mathrm{C}$ in the fixative containing $12 \%$ sucrose $(\mathrm{w} / \mathrm{v})$. Brains were frozen in hexanes cooled in powdered dry ice and immediately stored at $-70^{\circ} \mathrm{C}$ until sectioning at a later date. Eight series of one-in-eight, $15-\mu \mathrm{m}$-thick frontal sections were cut through the rostral hypothalamus and saved in ice-cold potassium PBS, $\mathrm{pH} 7.4$, containing $0.25 \%$ paraformaldehyde; sections were handled and stored as described previously (Watts and Sanchez-Watts, 1995a). Adjacent sections were saved for thionin staining.

Because the anesthesia required for perfusion precluded the measurement of plasma ACTH and corticosterone, a second batch of animals treated in the same manner as the first was killed by rapid decapitation. Trunk blood was collected in two cooled vials, coated with either EDTAsaline for ACTH assay or heparin-saline for corticosterone assay. Small samples from the heparinized blood were used for hematocrit and osmolality measurements. An index of the plasma volume deficit was derived from the hematocrit using the following relationship: [(hematocrit $_{\text {PEG }}-$ hematocrit $t_{\text {mean control }} /($ hematocrit mean control $\left.)\right] \times 100$. Thymuses were removed from animals after decapitation, blotted dry, and weighed. Because thymus weights are negatively correlated with $\log _{10}$ plasma corticosterone concentrations in a manner that is dependent only on glucocorticoid receptors (Dallman et al., 1987; Watts and SanchezWatts, 1995c), they provide an additional dependent variable for determining the bioactivity of circulating corticosterone concentrations. This measurement is particularly useful for assessing the long-term efficacy of circulating corticosterone during extended periods of DE, because characterizing the varying dynamics of plasma corticosterone concentrations is not easily determined without frequent sequential blood samples (Watts, 1992, 2000).

In a separate experiment designed to determine the effects of corticosterone on the CRH mRNA response to sustained hypovolemia, rats maintained throughout with water were bilaterally ADX under halothane anesthesia using flank incisions. At this time they were given a subcutaneous capsule containing either 25,50 , or $100 \mathrm{mg}$ of corticosterone (Innovative Research of America, Sarasota, FL). The time course of corticosterone release from these capsules together with their effects on CRH mRNA levels and thymus weights have been characterized in previous publications (Swanson and Simmons, 1989; Watts and SanchezWatts, 1995c; Tanimura and Watts, 1998). Six days later, rats were given a subcutaneous injection of either $40 \%$ PEG or vehicle (four to six animals per corticosterone capsule group), as described above. After 5 $\mathrm{hr}$, rats were rapidly anesthetized with tribromoethanol and then perfused as just described. A $6 \mathrm{~d}$ period was chosen in this experiment to ensure that mRNA levels had stabilized after adrenalectomy and capsule implantation (Swanson and Simmons, 1989). Thymuses were removed after perfusion and weighed. Brains were processed as described above to measure relative $\mathrm{CRH}$ mRNA levels in the PVH. Determinations of both thymus weights and CRH mRNA were made in the majority but not all animals.

All animal procedures were approved by the Institutional Animal Care and Use Committee of the University of Southern California.

In situ hybridization. Sections were hybridized with ${ }^{35} \mathrm{~S}$-UTP-labeled cRNA probes transcribed from cDNA sequences encoding RNAs for parts of the following genes: preproCRH $(700 \mathrm{bp})$, preproenkephalin (ppENK; $935 \mathrm{bp}$ ), a $536 \mathrm{bp} P v u I I$ fragment complementary to the sequence within the single CRH intron, and rat c-fos $(2.1 \mathrm{kbp})$. Although AVP is colocalized with CRH in the PVHmp (Whitnall, 1993) and plays a significant role in regulating the ACTH response to some stressors (Antoni, 1993; Kovács et al., 2000), we did not measure AVP hnRNA or mRNA levels in this study, because sustained hypovolemia does not increase parvicellular $A V P$ gene expression (Tanimura et al., 1998). Furthermore, DE significantly increases circulating corticosterone, which in turn strongly inhibits the $A V P$ gene and its response to hypovolemia (Kovács et al., 2000; Tanimura and Watts, 2000). It seemed reasonable to assume that combining these stressors would be ineffective at activating this gene.

cRNA probes were synthesized using the Promega (Madison, WI) Gemini kit and the appropriate RNA polymerase. The characterization of all probes has been reported previously (Watts, 1992; Watts and Sanchez-Watts, 1995a; Tanimura et al., 1998). In situ hybridization with the ${ }^{35}$ S-labeled cRNA probes was performed as described previously (Watts and Sanchez-Watts, 1995a; Kovács and Sawchenko, 1996a) with posthybridization modifications to the $\mathrm{CRH}$ hnRNA hybridization as follows. After the RNase incubation at $37^{\circ} \mathrm{C}$ and room temperature washes from 4 to $0.1 \times \mathrm{SSC}$, slides were incubated at $70^{\circ} \mathrm{C}$ for $30 \mathrm{~min}$ with slight agitation every $10 \mathrm{~min}$. Sections were exposed to Microvision C x-ray film (Diagnostic Imaging Inc., Mira Loma, CA) for appropriate exposure periods $(2-42 \mathrm{~d})$, dipped in nuclear track emulsion (Kodak NTB-2, diluted 1:1 with distilled water; Kodak, Rochester, NY), exposed for 5-42 d, developed, and counterstained with thionin.

Semiquantitation of ${ }^{35} S-U T P-c R N A$ hybridization. Mean gray levels of the RNA hybridization signals in the Nissl-defined subdivisions of the $\mathrm{PVH}$ were measured from images on Microvision C x-ray film as described previously (Watts and Sanchez-Watts, 1995a; Watts et al., 1995). Parcellation of the PVH was determined using the scheme and nomenclature of Swanson (1998). We have previously demonstrated the linearity of the in situ hybridization signal response on the x-ray film and our detection system (Tanimura et al., 1998).

Radioimmunoassays. Plasma corticosterone and ACTH concentrations were measured in duplicate unextracted samples as described previously (Tanimura et al., 1998) using a $\left[{ }^{125} \mathrm{I}\right]$ corticosterone or $\left[{ }^{125} \mathrm{I}\right] \mathrm{ACTH}$ double antibody radioimmunoassay supplied in kit form (ICN Biochemicals, Costa Mesa, CA). The lower sensitivity limits were $12.5 \mathrm{ng} / \mathrm{ml}$ and $15 \mathrm{pg} / \mathrm{ml}$, and the intra-assay coefficient of variation was $<8.1$ and $9.6 \%$ for corticosterone and ACTH, respectively. All samples were measured in single assays.

Statistical analysis. The significance of differences in osmolalities, hematocrits, and RNA hybridizations was determined across treatment groups using one-way ANOVA, followed by Dunnett's two-tailed post hoc test; values from animals given water to drink and injections of isotonic saline were used as controls. The effects of saline or PEG injections on thymus weights or CRH mRNA levels in ADX animals with corticosterone implants were determined by analysis of covariance. $p<$ 0.05 was regarded as being statistically significant. All statistical analyses were performed using Excel (Mac version 5.0; Microsoft, Seattle, WA) and Systat (Mac version 5.2). 
Table 1. Effect of sustained hypovolemia on mean \pm SEM thymus weights, plasma osmolaties, and hematocrits from animals given either water (W) or $2.5 \%$ hypertonic saline (HS) to drink for $3 \mathrm{~d}$, followed by a $5 \mathrm{ml}$ subcutaneous injection of $0.9 \%$ saline (Veh) or $40 \%$ PEG, and killed $5 \mathrm{hr}$ later

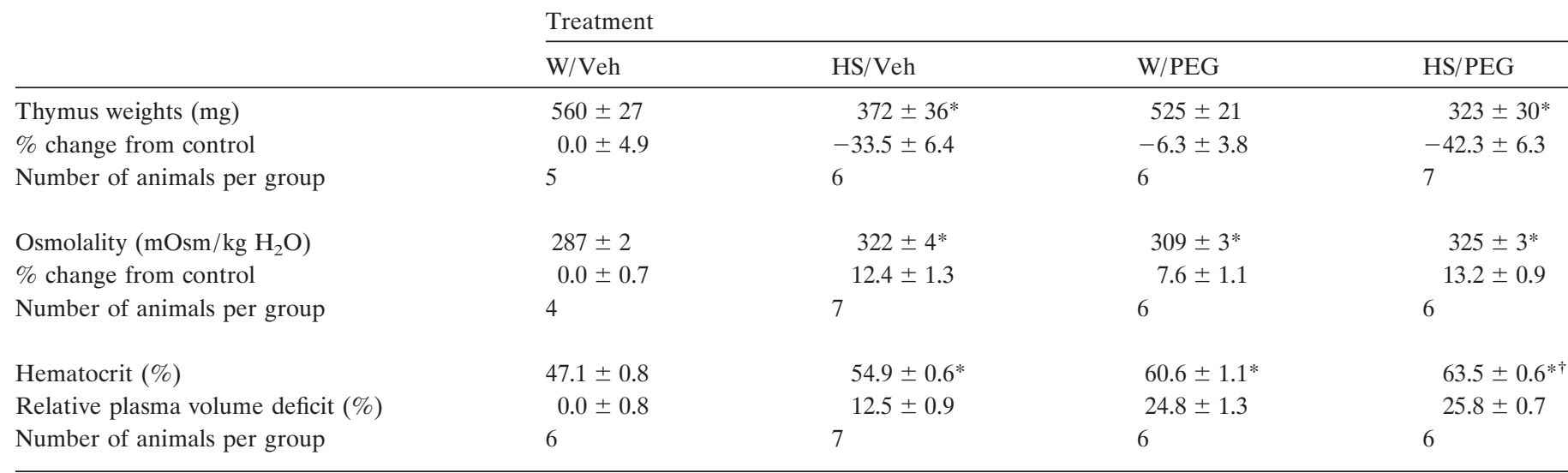

Relative plasma deficit was calculated using the mean W/Veh value used as a control for all groups.

${ }^{*} p<0.01$ or greater versus $\mathrm{W} /$ Veh animals.

${ }^{\dagger} p<0.01$ or greater versus appropriate non-PEG-injected controls.

\section{RESULTS}

\section{Effects of dehydration on thymus weights, plasma osmolality, and hematocrit}

Table 1 shows that drinking $2.5 \%$ saline for $3 \mathrm{~d}$ led to increased plasma osmolalities in all animals. Animals drinking water and injected with $40 \%$ PEG also showed increased plasma osmolality, although the size of this increase was significantly smaller than that seen after hypertonic saline ingestion and was most likely a result of the increased plasma protein concentrations resulting from hypovolemia (Stricker and Jalowiec, 1970). Plasma sodium levels are reduced by this treatment (Watts and Sanchez-Watts, 1995a). Three days of drinking $2.5 \%$ saline led to a significant reduction in thymus weights that was not further affected by PEG injection (Table 1).
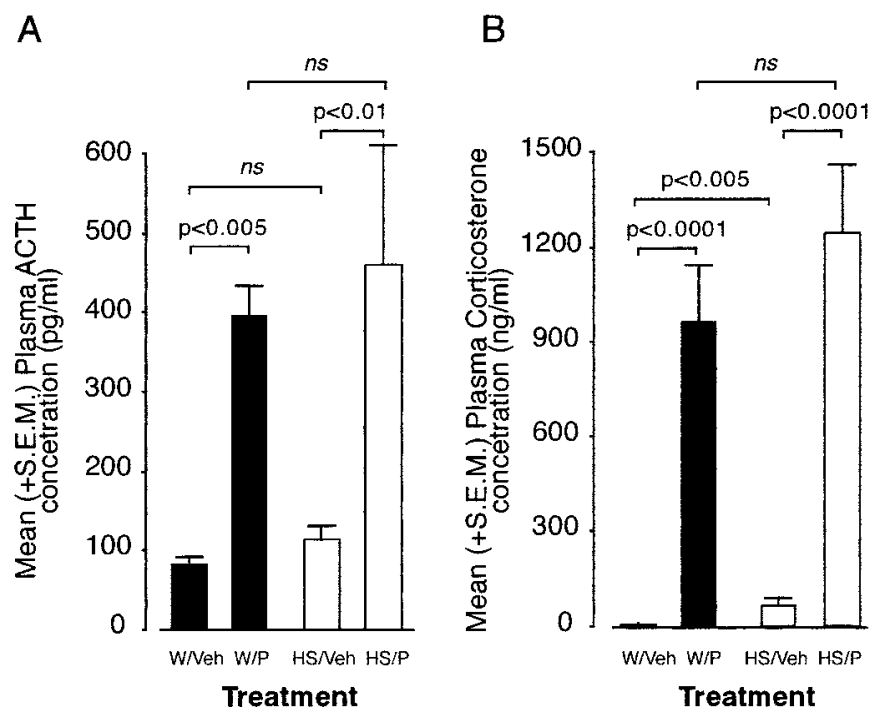

Figure 1. The effect of drinking either water $(W)$ or hypertonic saline for $3 \mathrm{~d}(H S)$ on the mean + SEM plasma concentrations of ACTH $(A)$ and corticosterone $(B)$ measured $5 \mathrm{hr}$ after either subcutaneous vehicle $(V e h)$ or PEG $(P)$ injections. $n s$, Not significant.
In animals drinking water, PEG injections were followed $5 \mathrm{hr}$ later by a significant reduction in plasma volume as reflected by increased hematocrits (Table 1). Three days of ingestion of hypertonic saline was followed by a significant reduction in plasma volume in animals injected with isotonic saline, but this was then reduced much further in the DE animals injected with PEG (Table 1).

Drinking hypertonic saline had no effect on the mean plasma $\mathrm{ACTH}$ concentration in animals injected with saline vehicle but did significantly increase mean plasma corticosterone concentrations (Fig. 1). These data are consistent with the existence of
A

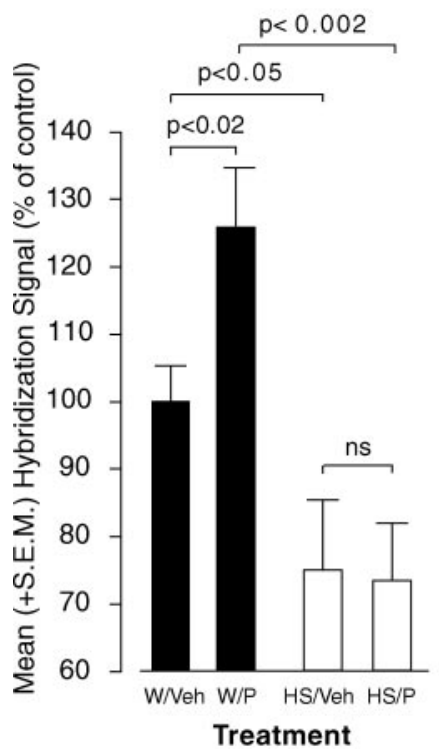

B

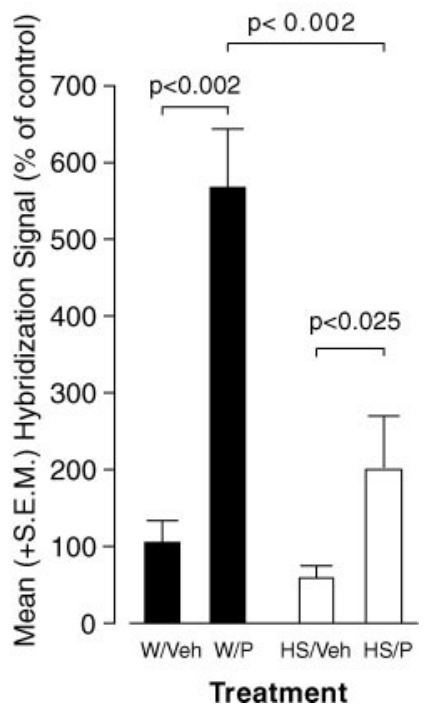

Figure 2. The effect of drinking either water $(W)$ or hypertonic saline for $3 \mathrm{~d}(H S)$ on the mean + SEM CRH mRNA $(A)$ and CRH hnRNA $(B)$ levels in the medial parvicellular part of the hypothalamic paraventricular nucleus measured $5 \mathrm{hr}$ after either subcutaneous vehicle (Veh) or PEG $(P)$ injections. 


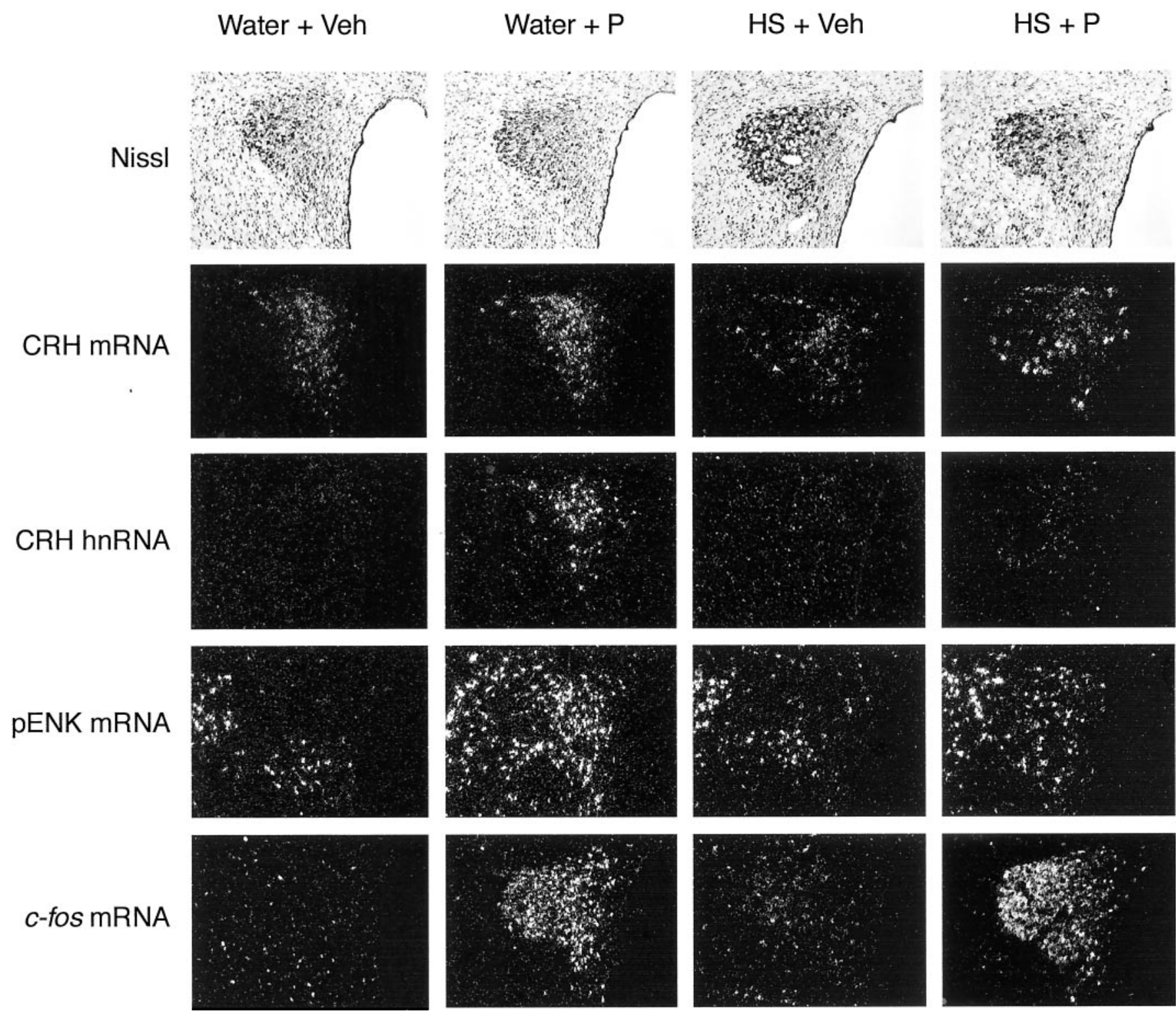

Figure 3. Photomicrographs of the hypothalamic paraventricular nucleus [approximately level 26 of Swanson (1998)] showing the effects of drinking either water or hypertonic saline for $3 \mathrm{~d}(H S)$ on the response $5 \mathrm{hr}$ later to either subcutaneous vehicle $($ Veh $)$ or PEG $(P)$ injections of CRH mRNA, CRH hnRNA, ppENK mRNA, and c-fos mRNA as detected by in situ hybridization. The top row shows adjacent thionin-stained sections (Nissl). Each column shows adjacent sections from one animal chosen as representative of each treatment.

non-ACTH-dependent mechanisms for increasing plasma corticosterone in DE animals. We have suggested previously that changes in corticosterone catabolism contribute to this effect (Watts, 2000), perhaps mediated by reduced hepatic clearance rates (Woodward et al., 1991). Mean plasma ACTH and corticosterone concentrations were robustly increased in all animals injected with PEG; drinking water or hypertonic saline had no significant effect on the mean concentration attained by either hormone $5 \mathrm{hr}$ after PEG injections.

\section{Effects of dehydration on the response of CRH hnRNA and mRNA levels to hypovolemia}

For animals drinking water, CRH mRNA levels in the PVHmp were significantly increased $5 \mathrm{hr}$ after PEG injections (Figs. $2 A$, 3 ). Figures $2 A$ and 3 also show that $3 \mathrm{~d}$ of drinking $2.5 \%$ hypertonic saline significantly reduced the levels of CRH mRNA in the PVHmp and completely suppressed its response to PEG at this time.

CRH hnRNA levels were significantly increased above control levels $5 \mathrm{hr}$ after PEG injections in animals provided with drinking water (Figs. $2 B, 3$ ). Although these hnRNA responses to PEG injections were still elevated above control values in animals given hypertonic saline to drink, they were significantly attenuated when compared with responses present in animals drinking water. The reason why CRH mRNA levels were unaffected by hypovolemia in dehydrated animals while hnRNA levels increased (albeit in a significantly blunted manner) is unclear. However, it may be related to the technical difficulty of measuring small changes in the relatively large cytoplasmic mRNA pool. Other groups have reported a similar discrepancy in response to some stressors (Kovács and Sawchenko, 1996). 
A

Figure 4. The effect of drinking either water $(W)$ or hypertonic saline for $3 \mathrm{~d}$ $(H S)$ on the mean + SEM level of preproenkephalin mRNA $(A)$ and c-fos mRNA $(B)$ in the medial parvicellular part of the hypothalamic paraventricular nucleus and c-fos mRNA in the posterior magnocellular part of the hypothalamic paraventricular nucleus $(C)$ measured 5 $\mathrm{hr}$ after either subcutaneous vehicle $(\mathrm{Veh})$ or PEG $(P)$ injections.
B
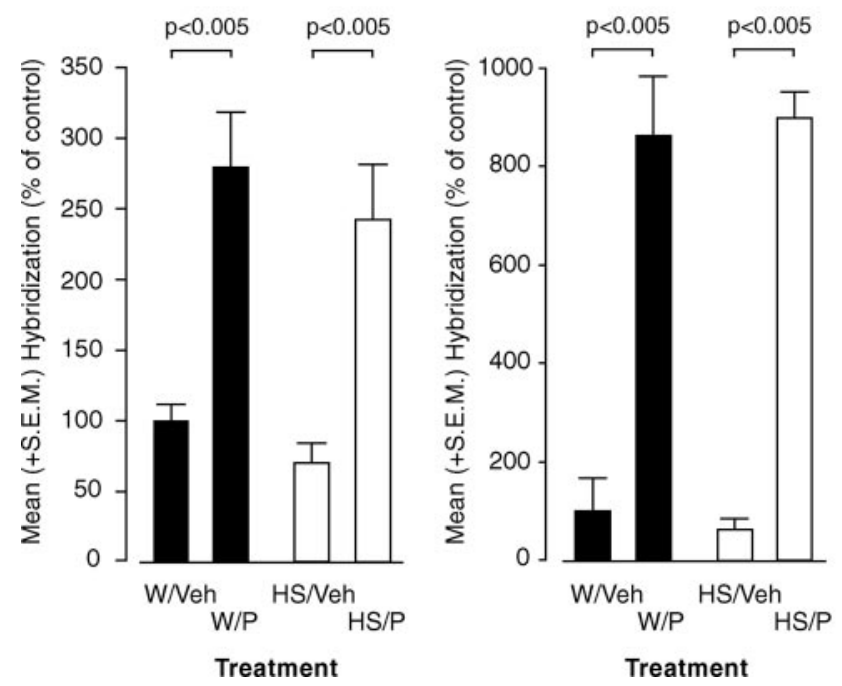

C

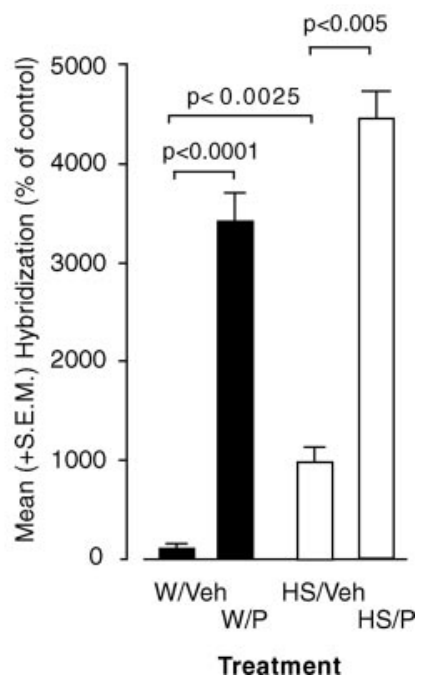

B
Figure 5. Thymus weights $(A)$ and $\mathrm{CRH}$ mRNA levels in the medial parvicellular part of the hypothalamic paraventricular nucleus $(B)$ were significantly correlated to the $\log _{10}$ plasma corticosterone concentration in ADX animals given a subcutaneous pellet containing various doses of corticosterone and injected with either $0.9 \%$ saline vehicle $(\bigcirc$; dashed line $)$ or $40 \%$ PEG (-; solid line). PEG injections did not effect either the slope or the $\mathrm{Y}$ intercept of the relationship between corticosterone and thymus weights but did significantly increase the $\mathrm{Y}$ intercept of the relationship between corticosterone and CRH mRNA levels. See Results for levels of statistical significance.
A

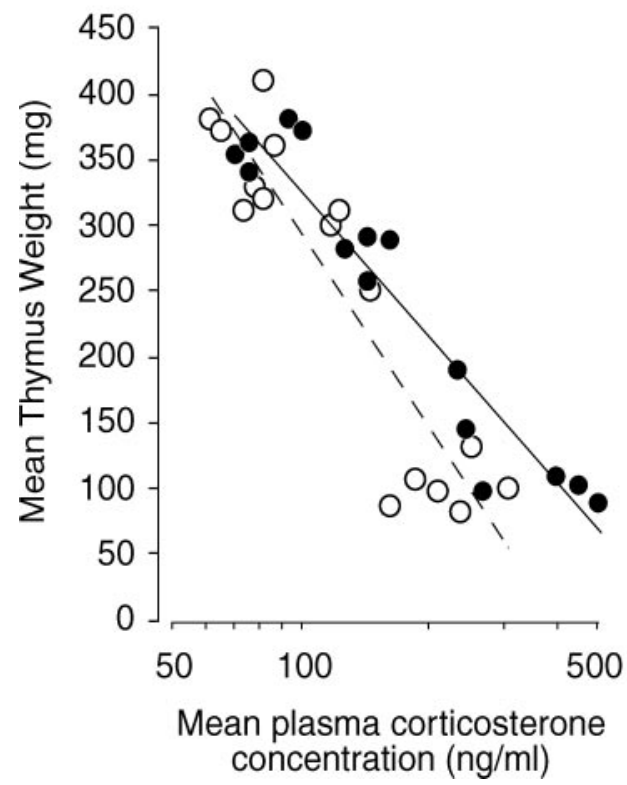

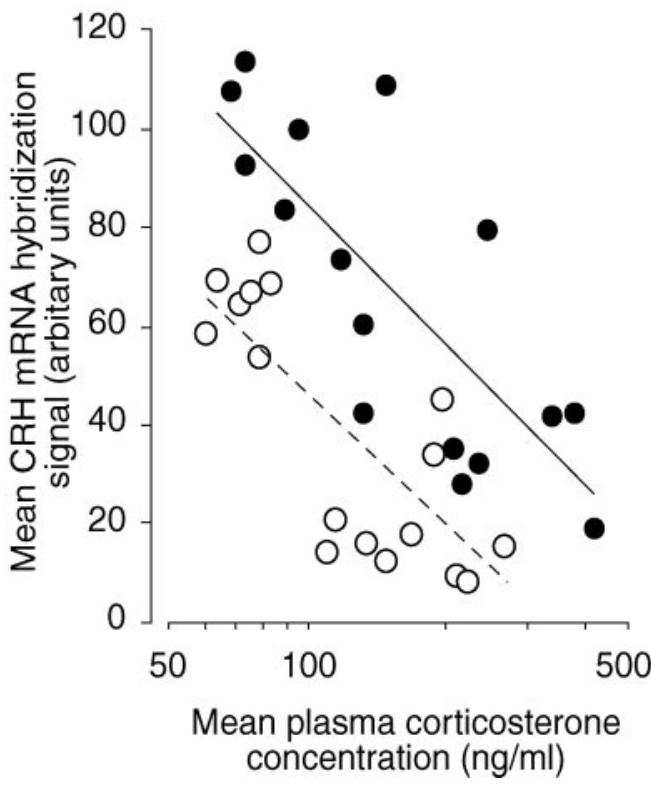

\section{Effects of dehydration on the response of c-fos and ppENK mRNA levels to hypovolemia}

Levels of both ppENK (Figs. 3, 4A) and c-fos (Figs. 3, 4B) mRNAs in the PVHmp were unaffected by drinking hypertonic saline, but both were significantly increased $5 \mathrm{hr}$ after PEG injections. The magnitude of the increase in ppENK and c-fos mRNA levels after hypovolemia was unaffected by drinking hypertonic saline (Figs. 3, 4A,B).

Figures 3 and $4 C$ show that c-fos mRNA was significantly increased in the posterior magnocellular part of the $\mathrm{PVH}$ (PVHpm) in animals drinking hypertonic saline and injected with saline vehicle. However, hypovolemia also increased c-fos mRNA levels in the PVHpm in both groups of animals. These data support the idea that DE does not globally suppress gene responses to hypovolemia in the neuroendocrine hypothalamus. In fact, in contrast to parvicellular CRH neurons, the effects of DE and sustained hypovolemia appear to be integrated in an additive manner in magnocellular neuroendocrine neurons, at least as far as c-fos gene expression is concerned.

\section{Effects of corticosterone on the response of thymus weights and CRH mRNA levels to hypovolemia in euhydrated ADX animals}

Plasma corticosterone concentrations in capsule-implanted ADX animals ranged from 62 to $508 \mathrm{ng} / \mathrm{ml}$ (Fig. $5 A, B$ ). Figure $5 A$ shows that thymus weights were significantly correlated to the $\log _{10}$ plasma corticosterone concentration in animals injected with vehicle $\left(r^{2}=0.838 ; F=72.52 ; p<0.0001 ; n=16\right)$ or PEG $\left(r^{2}=\right.$ $0.912 ; F=133.96 ; p<0.0001 ; n=15)$. Analysis of covariance showed that PEG did not have a significant effect on corticosterone concentrations $(p=0.17)$ in animals used for the thymus weight determinations. Furthermore, injection with PEG had no significant effect on either the slope $(p=0.76)$ or the $\mathrm{Y}$ intercept ( $p=0.14)$ of the relationship between plasma corticosterone 
concentration and thymus weight. Although a direct comparison of absolute thymus weights was not possible because of the different methods used for killing (perfusion vs direct decapitation), comparing the relative reduction found in animals after $3 \mathrm{~d}$ of DE ( $38 \%$; Table 1) with those in corticosterone-replaced animals (Fig. 5A) suggested that mean plasma corticosterone concentrations of intact animals over the 3 period of dehydration were equivalent to that produced by $\sim 150 \mathrm{ng} / \mathrm{ml}$ corticosterone in the hydrated corticosterone-replaced animals.

Figure $5 B$ shows that there was a significant negative correlation between CRH mRNA levels in the PVHmp and the $\log _{10}$ concentration of corticosterone in both vehicle-injected animals $\left(r^{2}=0.519 ; F=16.20 ; p<0.002 ; n=17\right)$ and PEG-injected animals $\left(r^{2}=0.506 ; F=14.38 ; p<0.002 ; n=16\right)$. Analysis of covariance showed that PEG injection did not have a significant effect on corticosterone concentrations $(p=0.562)$ in animals used for CRH mRNA determinations. Like thymus weights, the slopes of the regression lines between plasma corticosterone concentration and CRH mRNA levels were not significantly different between animals injected with vehicle or PEG $(p=0.08)$. However, the $\mathrm{Y}$ intercept was significantly different between those animals injected with vehicle and those with PEG $(p<$ 0.001).

\section{DISCUSSION}

We have shown previously that sustained hypovolemia activates CRH gene transcription in PVHmp neurons within $2 \mathrm{hr}$ of the onset of hypovolemia and is maintained for the duration of the stress (Tanimura et al., 1998). Chronic DE however, downregulates CRH synthesis in these same neurons and requires at least 3 d to manifest its effects on $C R H$ gene expression (Young, 1986; Dohanics et al., 1990; Watts, 1992; Aguilera et al., 1993; Watts et al., 1995; Kay-Nishiyama and Watts, 1999). We now show that the consequences of DE also restrain $C R H$ gene activation in response to sustained hypovolemia to the extent that CRH mRNA is no longer significantly increased after PEG injections. The fact that increased CRH hnRNA levels are also strongly attenuated in these circumstances suggests that DE inhibits, at least in part, the effects of the PVHmp afferent mechanisms used by sustained hypovolemia either before or during $C R H$ gene transcription. Because the $C R H$ gene response to hypovolemia is suppressed, whereas those of the $p p E N K$ and c-fos genes remain unaffected means that this inhibition is not directed nonspecifically at PVHmp neurons. This conclusion is also supported by the fact that the magnitude of the ACTH response to hypovolemia in DE animals is indistinguishable at $5 \mathrm{hr}$ from control animals, and shows that neuroendocrine CRH neurons can still release ACTH secretogogues in a stimulus-dependent manner into the hypophysial vasculature. Whether these observations mean that gene expression and peptide release are each driven by separate afferent mechanisms, or whether DE preferentially suppresses intracellular mechanisms that control $C R H$ gene expression is not yet clear. However, our previous observations showing that the onsets of peptide release and gene activation have different stressintensity thresholds (Tanimura et al., 1998) are consistent with the notion that there is at least some degree of separation between the mechanisms that activate secretion and gene transcription.

It is reasonable to consider that the opposing actions of DE and sustained hypovolemia on $C R H$ gene expression are, like those of other stressors, mediated by two processes. First, the two sets of neural afferents respectively encode the sensory information gen- erated by DE and hypovolemia and converge on the PVH. This convergence may occur directly at $\mathrm{CRH}$ neurons in the $\mathrm{PVH}$, or more distally in sets of neurons that then project to the PVH. Second, corticosterone-dependent mechanisms involve actions on $\mathrm{CRH}$ neurons themselves as well as more indirect effects mediated by afferents to the PVHmp (Herman and Cullinan, 1997; Kovács and Sawchenko, 2000). With regard to neural afferents, the reduced $\mathrm{CRH}$ gene expression that follows DE requires cells in the vascular organ of the lamina terminalis but not ascending projections from the hindbrain (Kovács and Sawchenko, 1993). DE also increases neuropeptide gene expression in a subset of lateral hypothalamic neurons that project to the $\mathrm{PVH}$, which may also modulate CRH neurons (Champagne et al., 1998; Watts et al., 1999). In contrast, hypovolemia activates CRH gene expression in the PVHmp using a different set of neural afferents. These include angiotensinergic inputs from the subfornical organ and ascending catecholaminergic projections from the hindbrain that encode various types of hemodynamic sensory information (Chan and Sawchenko, 1994; Pacák and Palkovits, 2001).

The second important regulator of CRH synthesis in the PVHmp is corticosterone. Many workers have demonstrated its robust negative feedback relationship with CRH mRNA levels in the PVHmp (for review, see Watts, 1996). In unstressed rats, this is seen as a negative logarithmic correlation between plasma corticosterone concentrations and CRH mRNA levels (Watts and Sanchez-Watts, 1995c). At least part of the mechanism used by corticosterone to reduce CRH mRNA levels involves an action on $C R H$ gene transcription; CRH hnRNA levels are significantly increased in ADX animals when compared with intact rats or ADX rats with subnormal corticosterone replacement (Tanimura and Watts, 1998, 2000; Kovács et al., 1998, 2000). However, a variety of temporal and molecular data suggest that unlike its control of the AVP gene (Burke et al., 1997), corticosterone does not reduce $\mathrm{CRH}$ mRNA by direct receptor-mediated inhibitory actions on $C R H$ gene transcription (Ma et al., 1997b; Reichardt et al., 1998; Tanimura et al., 1998). Presumably, other nongenomic actions that target the processes preceding transcriptional activation are important for the negative feedback actions of corticosterone (Rosen et al., 1992; Guardiola-Diaz et al., 1996).

Corticosterone is required for the actions on $C R H$ gene expression of both stressors used in this experiment. Thus, DEdependent reductions of CRH mRNA do not occur in ADX animals (Watts and Sanchez-Watts, 1996b), whereas the level of circulating corticosterone present before the stress determines how the $C R H$ gene responds to sustained hypovolemia (Tanimura and Watts, 1998, 2000). It is important to note that for hypovolemia, the dose of corticosterone that normalizes $C R H$ gene responses of ADX rats is well below the maximum corticosterone values seen during either mild stress or normal circadian variations (Tanimura and Watts, 1998, 2000). This observation is similar to that reported by Dallman et al. (1987), who showed that corticosterone replacement at levels around the circadian mean, $30-60 \mathrm{ng} / \mathrm{ml}$, will normalize a variety of components in the pituitary-adrenocortical system.

Although these negative feedback actions of corticosterone are consistent with the idea that the elevated corticosterone concentrations seen during DE (Watts, 1992; Watts et al., 1999) might be responsible for suppressing $C R H$ gene responses to sustained hypovolemia, our data now suggest that this is unlikely, because high levels of corticosterone did not suppress the $C R H$ gene response to PEG in non-DE animals. Thus, we show that during hypovolemia there is still a significant negative relationship be- 
tween circulating corticosterone concentrations and the $\mathrm{CRH}$ mRNA levels attained during the stress, the slope of which is not significantly different from that in nonstressed animals. Critically however, the regression line is significantly shifted to the right for the relationship between corticosterone and CRH mRNA levels after PEG, but not, as one might expect, thymus weights. These data show that if circulating corticosterone is held between the circadian mean and $\sim 300 \mathrm{ng} / \mathrm{ml}$ before the stress occurs, it does not inhibit the ability of the $C R H$ gene to respond to PEG, a finding consistent with our previous study (Tanimura and Watts, 1998). The principal effect of corticosterone on the $C R H$ gene response to hypovolemia, therefore, is to control prestress mRNA levels; it has much less of an effect on the magnitude of the gene response. Thus, our data show that although corticosterone is required, the chronically elevated plasma concentrations seen in DE animals cannot be responsible for inhibiting the CRH mRNA response to sustained hypovolemia, which leaves an afferentdependent mechanism as the most parsimonious explanation.

Collectively, our observations show that part of the integrative control of $C R H$ gene expression in PVHmp neurons requires interactions between the different sets of neural afferents that encode the diverse types of sensory information generated by physiological stimuli. In other words, how one set of neural afferents affects $C R H$ gene expression at any one time is dependent on the status of others. We suggest that the reason the $C R H$ gene response to hypovolemia is greatly attenuated by $\mathrm{DE}$ is because it changes the state of DE-sensitive PVHmp afferents (Kovács and Sawchenko, 1993; Watts, 2001) in such a way as to reduce the efficacy of the afferents that normally enable sustained hypovolemia to activate the $C R H$ gene.

In this model, the way corticosterone controls the gene response to a particular stressor is dependent on which set of afferents is activated at a particular time. Thus, when circulating corticosterone is at or above the circadian mean, it negatively regulates the lower level of an operating range within which the $\mathrm{CRH}$ gene might respond to stressors. Whether corticosterone influences the magnitude of the gene response is determined by the nature of the stressor and the afferent set it uses. With hypovolemia, which is encoded by one set of afferents, we show that corticosterone does not inhibit the $C R H$ gene response. However, corticosterone has a much greater inhibitory action on the $C R H$ gene response to more complex stressors, such as ether inhalation, that are encoded by different afferents (Kovács et al., 2000). Our interpretation regarding steroid-sensitive and -insensitive gene activation is reminiscent of a similar dichotomy for ACTH secretory responses to various stressors (Keller-Wood and Dallman, 1984; Thrivikraman and Plotsky, 1993), the basis of which is reportedly related to differential activation of PVHmp afferent sets (Thrivikraman et al., 2000; Pacák and Palkovits, 2001).

Finally, these integrative mechanisms also target neuropeptide genes that are coexpressed with CRH. This is clear for the AVP gene, where corticosterone has a profound influence on the magnitude of its response to stress (Tanimura et al., 1998; Kovács and Sawchenko, 2000; Tanimura and Watts, 2000). However, corticosterone and DE have no detectable effect on the ppENK gene or its response to sustained hypovolemia (Watts, 1992; Watts and Sanchez-Watts, 1995c; Tanimura and Watts, 1998). In summary, this entire integrative process might be considered as a form of corticosterone-dependent switching that determines how the expression of peptide genes in neuroendocrine $\mathrm{CRH}$ neurons responds to differential activation of their afferent inputs.

\section{REFERENCES}

Aguilera G, Lightman SL, Kiss A (1993) Regulation of the hypothalamic-pituitary-adrenal axis during water deprivation. Endocrinology 132:241-248.

Antoni FA (1993) Vasopressinergic control of pituitary adrenocorticotropin secretion comes of age. Front Neuroendocrinol 14:76-122.

Burke ZD, Ho MY, Morgan H, Smith M, Murphy D, Carter D (1997) Repression of vasopressin gene expression by glucocorticoids in transgenic mice: evidence of a direct mechanism mediated by proximal $5^{\prime}$ flanking sequence. Neuroscience 78:1177-1185.

Champagne D, Beaulieu J, Drolet G (1998) CRFergic innervation of the paraventricular nucleus of the rat hypothalamus: a tract-tracing study. J Neuroendocrinol 10:119-131.

Chan RK, Sawchenko PE (1994) Spatially and temporally differentiated patterns of c-fos expression in brainstem catecholaminergic cell groups induced by cardiovascular challenges in the rat. J Comp Neurol 348:433-460.

Dallman MF, Akana SF, Cascio CS, Darlington DN, Jacobson L, Levin N (1987) Regulation of ACTH secretion: variations on a theme of B. Recent Prog Horm Res 43:113-173.

Dohanics J, Kovács KJ, Makara GB (1990a) Oxytocinergic neurons in rat hypothalamus. Dexamethasone-reversible increase in their corticotropin-releasing factor-41-like immunoreactivity in response to osmotic stimulation. Neuroendocrinology 51:515-522.

Dohanics J, Kovács KJ, Folly G, Makara GB (1990b) Long-term salt loading impairs pituitary responsiveness to ACTH secretagogues and stress in rats. Peptides 11:59-63.

Guardiola-Diaz HM, Kolinske JS, Gates LH, Seasholtz AF (1996) Negative glucorticoid regulation of cyclic adenosine $3^{\prime}, 5^{\prime}$-monophosphatestimulated corticotropin-releasing hormone-reporter expression in AtT-20 cells. Mol Endocrinol 10:317-329.

Herman JP, Cullinan WE (1997) Neurocircuitry of stress: central control of the hypothalamo-pituitary-adrenocortical axis. Trends Neurosci 20:78-84.

Kay-Nishiyama C, Watts AG (1999) Dehydration modifies somal CRH immunoreactivity in the rat hypothalamus: an immunocytochemical study in the absence of colchicine. Brain Res 822:251-255.

Keller-Wood ME, Dallman MF (1984) Corticosteroid inhibition of ACTH secretion. Endocr Rev 5:1-24.

Kovács KJ, Sawchenko PE (1993) Mediation of osmoregulatory influences on neuroendocrine corticotropin-releasing factor expression by the ventral laminar terminals. Proc Natl Acad Sci USA 90:7681-7685.

Kovács KJ, Sawchenko PE (1996a) Sequence of stress-induced alterations in indices of synaptic and transcriptional activation in parvocellular neurosecretory neurons. J Neurosci 16:262-273.

Kovács KJ, Sawchenko PE (1996b) Regulation of stress-induced transcriptional changes in the hypothalamic neurosecretory neurons. J Mol Neurosci 7:125-133.

Kovács KJ, Arias C, Sawchenko PE (1998) Protein synthesis blockade differentially affects the stress-induced transcriptional activation of neuropeptide genes in parvocellular neurosecretory neurons. Brain Res Mol Brain Res 54:85-91.

Kovács KJ, Foldes A, Sawchenko PE (2000) Glucocorticoid negative feedback selectively targets vasopressin transcription in parvocellular neurosecretory neurons. J Neurosci 20:3843-3852.

Ma XM, Levy A, Lightman SL (1997a) Rapid changes in heteronuclear RNA for corticotrophin-releasing hormone and arginine vasopressin in response to acute stress. J Endocrinol 152:81-89.

Ma XM, Levy A, Lightman SL (1997b) Rapid changes of heteronuclear RNA for arginine vasopressin but not for corticotropin releasing hormone in response to acute corticosterone administration. J Neuroendocrinol 9:723-728.

Pacák K, Palkovits M (2001) Stressor specificity of central neuroendocrine responses: implications for stress-related disorders. Endocr Rev 22:502-548.

Reichardt HM, Kaestner KH, Tuckermann J, Kretz O, Wessely O, Bock R, Gass P, Schmid W, Herrlich P, Angel P, Schütz G (1998) DNAbinding of the glucocorticoid receptor is not essential for survival. Cell 93:531-541.

Rosen LB, Majzoub JA, Adler GK (1992) Effects of glucocorticoid on corticotropin-releasing hormone gene regulation by second messenger pathways in NPLC and AtT-20 cells. Endocrinology 130:2237-2244.

Stricker EM, Jalowiec JE (1970) Restoration of intravascular fluid volume following acute hypovolemia in rats. Am J Physiol 218:191-196.

Stricker EM, Vagnucci AH, McDonald RH, Leenan FH (1979) Renin and aldosterone secretions during hypovolemia in rats: relation to $\mathrm{NaCl}$ intake. Am J Physiol 237:R45-R51.

Swanson LW (1998) Brain maps: structure of the rat brain, Ed 2. Amsterdam: Elsevier Science Publishers.

Swanson LW, Simmons DM (1989) Differential steroid hormone and neural influences on peptide mRNA levels in CRH cells of the paraventricular nucleus: a hybridization histochemical study in the rat. J Comp Neurol 285:413-435.

Tanimura SM, Watts AG (1998) Corticosterone can facilitate as well as 
inhibit CRH gene expression in the rat hypothalamic paraventricular nucleus. Endocrinology 139:3830-3837.

Tanimura SM, Watts AG (2000) Adrenalectomy dramatically modifies the dynamics of neuropeptide and c-fos gene responses to stress in the hypothalamic paraventricular nucleus. J Neuroendocrinol 12:715-722.

Tanimura SM, Sanchez-Watts G, Watts AG (1998) Peptide gene activation, secretion, and steroid feedback during stimulation of rat neuroendocrine CRH neurons. Endocrinology 139:3822-3829.

Thrivikraman KV, Plotsky PM (1993) Absence of glucocorticoid negative feedback to moderate hemorrhage in conscious rats. Am J Physiol 264:E497-E503.

Thrivikraman KV, Nemeroff CB, Plotsky PM (2000) Sensitivity to glucocorticoid-mediated fast-feedback regulation of the hypothalamicpituitary-adrenal axis is dependent upon stressor specific neurocircuitry. Brain Res 870:87-101.

Watts AG (1992) Disturbance of fluid homeostasis leads to temporally and anatomically distinct responses in the levels of neuropeptide and tyrosine hydroxylase mRNAs within the hypothalamic paraventricular and supraoptic nuclei of the rat. Neuroscience 46:859-879.

Watts AG (1996) The impact of physiological stimulation on the expression of corticotropin-releasing hormone and other neuropeptide genes. Front Neuroendocrinol 17:281-326.

Watts AG (2000) Understanding the neural control of ingestive behaviors: helping to separate cause from effect with dehydration-associated anorexia. Horm Behav 37:261-283.

Watts AG (2001) Neuropeptides and the integration of motor responses to dehydration. Annu Rev Neurosci 24:357-384.
Watts AG, Sanchez-Watts G (1995a) Physiological regulation of peptide messenger RNA colocalization in rat hypothalamic paraventricular medial parvicellular neurons. J Comp Neurol 352:501-514.

Watts AG, Sanchez-Watts G (1995b) A cell-specific role for the adrenal gland in regulating CRH mRNA levels in rat hypothalamic neurosecretory neurones after cellular dehydration. Brain Res 687:63-70.

Watts AG, Sanchez-Watts G (1995c) Region-specific regulation of neuropeptide mRNAs in rat limbic forebrain neurones by aldosterone and corticosterone. J Physiol (Lond) 484:721-736.

Watts AG, Kelly AB, Sanchez-Watts G (1995) Neuropeptides and thirst: the temporal response of corticotropin-releasing hormone and neurotensin/neuromedin $\mathrm{N}$ gene expression in rat limbic forebrain neurons to drinking hypertonic saline. Behav Neurosci 109:1146-1157.

Watts AG, Sanchez-Watts G, Kelly AB (1999) Distinct and similar patterns of neuropeptide gene expression are present in rat hypothalamus following dehydration-induced anorexia or paired food restriction. J Neurosci 19:6111-6121.

Whitnall MH (1993) Regulation of the hypothalamic corticotropinreleasing hormone neurosecretory system. Prog Neurobiol 40:573-629.

Woodward CJ, Hervey GR, Oakey RE, Whitaker EM (1991) The effects of fasting on plasma corticosterone kinetics in rats. $\mathrm{Br} \mathrm{J}$ Nutr 66:117-127.

Young WS (1986) Corticotropin-releasing factor mRNA in the hypothalamus is affected differentially by drinking saline and by dehydration. FEBS Lett 208:158-162. 